\title{
Access, attitudes and training in information technologies and evidence-based medicine among medical students at University of Zimbabwe College of Health Sciences.
}

\author{
Swapnil Parve ${ }^{1}$, Ali Ershadi ${ }^{1}$, Alexandr Karimov ${ }^{1}$, Anne Dougherty ${ }^{2}$, \\ Chiratidzo E. Ndhlovu ${ }^{3}$, Midion M. Chidzonga ${ }^{3}$, Majid Sadigh ${ }^{1}$
}

1. Global Health Program, Western Connecticut Health Network, Danbury, CT, USA

2. Department of Obstetrics, Gynecology and Reproductive Sciences, University of Vermont College of Medicine, Burlington, VT, USA

3. Medical Education, University of Zimbabwe College of Health Sciences, Harare, Zimbabwe

\begin{abstract}
:
Background: The Medical Education Partnership Initiative, has helped to mitigate the digital divide in Africa.

The aim of the study was to assess the level of access, attitude, and training concerning meaningful use of electronic resources and EBM among medical students at an African medical school.

Methods: The study involved medical students at the University of Zimbabwe College of Health Sciences, Harare. The needs assessment tool consisted of a 21-question, paper-based, voluntary and anonymous survey.

Results: A total of $61 / 67(91 \%)$, responded to the survey. $60 \%$ of the medical students were 'third-year medical students'. Among medical students, $85 \%$ of responders had access to digital medical resources, but $54 \%$ still preferred printed medical textbooks. Although $25 \%$ of responders had received training in EBM, but only $7 \%$ found it adequate. $98 \%$ of the participants did not receive formal training in journal club presentation or analytical reading of medical literature, but $77 \%$ of them showed interest in learning these skills.

Conclusion: Lack of training in EBM, journal club presentation and analytical reading skills have limited the impact of upgraded technology in enhancing the level of knowledge. This impact can be boosted by developing a curriculum with skills necessary in using EBM.
\end{abstract}

Keywords: Information technologies, evidence-based medicine, medical students, University of Zimbabwe, College of Health Sciences.

DOI: http://dx.doi.org/10.4314/ahs.v16i3.29

Cite as: Parve S, Ershadi A, Karimov A, Dougherty A, Ndhlovu CE, Chidzonga MM, Sadigh M. Access, attitudes and training in information technologies and evidence-based medicine among medical students at University of Zimbabwe College of Health Sciences. Afri Health Sci 2016;16(3): 860-865. DOI: http://dx.doi.org/10.4314/abs.v16i3.29

\section{Introduction}

Over the last two decades, the use of modern information technology (IT) has developed at a breathtaking pace in all fields including medicine. ${ }^{1-3}$ Computers, tablets and smart phones are readily available even in low resource settings. The availability of medical applications, articles and eBooks for hand-held devices have made medical information readily accessible. ${ }^{1}$ Healthcare workers use

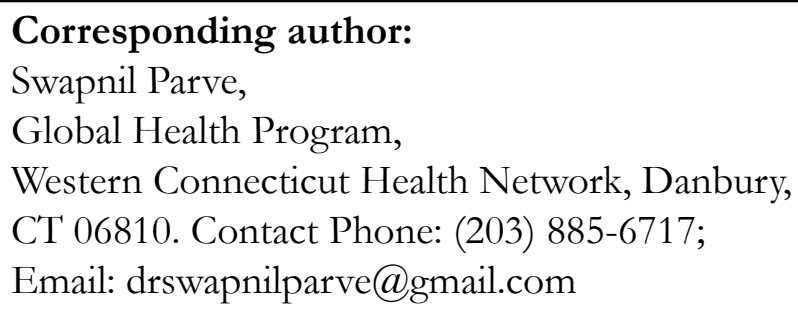

computers and hand-held devices for various purposes including, but not limited to up-to-date medical references. In alignment with the advances of technology, the evolution of evidence-based medicine (EBM) has also been pivotal for healthcare, changing the way of medical education, diagnosis and management in the developed world.

The question remains, how evenly has the IT revolution taken place? Multiple reports suggest that, a deep "digital divide" exists between Western countries and their African counterparts in terms of the technical features of medical education and learning, such as lack of necessary hardware, electronic medical resources, etc. ${ }^{4-9}$ Home to $15 \%$ of the world's population, sub-Saharan Africa has a mere $9.8 \%$ of internet users. ${ }^{10,11}$ Multiple factors are re- 
sponsible for this digital divide and include lack of infrastructure and resources, interrupted power supply, financial issues, and poor user acceptability. Additionally, when resource limited countries acquire technology; many healthcare professionals lack the training to utilize it.

In order to mitigate this digital divide, many international organizations have come forward with several initiatives. One such program is the Medical Education Partnership Initiative (MEPI). The MEPI program has significantly invested in the improvement of medical education in twelve sub-Saharan African countries with an aim to strengthen their health system by providing adequate resources, increasing the quality and quantity of medical graduates, promoting competency based curriculum development as well as encouraging research initiatives. ${ }^{12,13}$ As one of the results of MEPI, medical education in countries such as Zimbabwe has enjoyed significant technical growth, yet there remains a lag in their effective access and utilization of EBM.

In this study we determined the level of access, attitude, and training concerning meaningful use of electronic resources and EBM among medical students in University of Zimbabwe College of Health Sciences after the implementation of MEPI.

\section{Methods}

The University of Zimbabwe College of Health Sciences (UZCHS), located in Harare, Zimbabwe, is one of the oldest medical schools in Africa and is a recipient of MEPI initiative. ${ }^{13,14}$ Much of the infrastructure including computers and electronic resources were updated follow- ing the MEPI grant.

We conducted a survey among medical students, at UZCHS. Participation in this study was voluntary and anonymous.

A paper-based questionnaire consisting of 21 questions was utilized to determine the level of access, attitude, and training concerning meaningful use of electronic resources and EBM.

The participants were asked questions such as: whether they own a computer or they have access to free Internet? What are their most used medical references? Whether they were trained in EBM and journal club presentation and whether those classes, if any, met their needs?

After a brief introduction regarding goals of the study, the investigator distributed the questionnaire among 67 participants.

The gathered data was analyzed using JMP statistical software version 10.0. Descriptive statistics were used for analysis.

Prior to the initiation of the study, Institutional Review Board's approval of UZCHS and WCHN was obtained. Furthermore, informed consent was sought for all participants in the study and the information from the respondents has been treated with confidentiality.

\section{Results}

The response rate to the survey was $91 \%(61 / 67) .60 \%$ (37/61) of the medical students identified themselves as 'third-year medical students'. (Table 1).

Amongst all responders, 95\% (58/61) owned a computer. Of all responders, $85 \%(52 / 61)$ had internet access, $83 \%$

\section{Table 1. Study population}

\begin{tabular}{ll}
\hline Study population & No. (\%) \\
Total number of Medical students participated & 67 \\
Medical students responded & $61 / 67(91 \%)$ \\
Third year medical students & $37 / 61(60 \%)$ \\
\hline
\end{tabular}


$(43 / 52)$ of whom had free access. The majority of responders were comfortable in using various online search engines, including Google (83\%), Wikipedia (72\%) and PubMed/Medline (69\%) (Table 2). 54\%(33/61) of respondents used print books primarily to access medical information. Electronic media and electronic books were primary sources for $25 \%(15 / 61)$ and $11 \%(7 / 61)$ of respondents respectively. Three percent $(2 / 61)$ of the applicants used print journals as their medical information resource and $11 \%(7 / 61)$ of the participants did not to respond.

$70 \%$ (43/61) of responders did not receive formal training in EBM and 10\% (6/61) left the question un- answered. Among 25\% (15/61) of responders, who received a formal training in EBM, 93\% (14/15) found it inadequate. Of the 70\% (43/61) participants who did not receive formal training, $88 \%(38 / 43)$ wished to receive EBM training. 98\% (60/61) of responders did not receive formal training in journal club presentation and scientific reading skills, among which $77 \%$ (46/60) showed interest in learning these skills. Amongst all participants, 64\% (39/61) felt more or less confident in their capabilities of distinguishing the value of medical literature with only $8 \%$ feeling extremely secure of themselves.

\section{Discussion}

IT has played an essential role in accessibility of medical

\section{Table 2. Popularity of multiple search engines utilized when accessing multiple resources/engines}

\begin{tabular}{ll}
\hline Search engine & No. in percent \\
Google & $83 \%$ \\
Wikipedia & $72 \%$ \\
Pubmed/Medline & $69 \%$ \\
eMedicine & $14 \%$ \\
Google Scholar & $12 \%$ \\
Medscape & $10 \%$ \\
HINARI & $9 \%$ \\
UptoDate & $5 \%$ \\
\hline
\end{tabular}

literature and information in the developed world. Medical students in North America and Europe are expected to not only be acquainted with computers but to use them comprehensively in their training and management of healthcare. Typically, medical students in the developed world receive training in EBM and this translates into high user acceptability.

Established in 1963, the medical school at UZCHS started to function as an affiliate of University of Birmingham, United Kingdom and was one of the premier institutions in the region, until political and financial crises affected it. ${ }^{13}$ Most of the academic institutions in Africa have a parallel history because of constant political erosions and financial difficulties. Since the quality of healthcare delivery is related to the quality of medical education, the US government started the Medical Education and Partnership Initiative. MEPI is a \$US 130 million, five-year program (launched in September 2010), funded by the United States President's Emergency Plan for AIDS Relief (PEPFAR) and the US National Institutes of Health (NIH). It is administered by the NIH and the US Health Resources and Services Administration (HRSA) and has largely been responsible for upgrading the medical education in sub-Saharan Africa. ${ }^{15}$

Computer based education began to gain momentum in the Zimbabwe only after 2010, when funding increased 
through MEPI. Subsequently, UZCHS has made a rapid progress in developing the skills of faculty members, developing new curriculums and replacing the outdated IT infrastructure for medical education with new one. As a result, UZCHS has access to better internet bandwidth, computer hardware, and software needs. Furthermore, MEPI funding also provided the much needed element of sustainability. ${ }^{13}$

Multiple studies suggest that healthcare workers in resource limited settings access computers, hand-held devices and a broad range of medical resources, yet remain uncomfortable using computers for medical related activities or have limited knowledge on using EBM., ${ }^{3,16}$ This is consistent with our study findings, even though most of our responders had an access to computer and internet, majority of them preferred textbooks. Currently, most libraries in low and middle income countries are filled with outdated literature and resources. Even though, with MEPI funding almost all the partnering institutions updated their library resources, the high cost of these books and their frequent updates make it difficult to purchase them regularly.

Our findings also show that amongst multiple search engines utilized when accessing the several resources/ engines, Google was most popular search engine (83\%), while HINARI was being used by just $9 \%$ of the users. (Table 2). Several initiatives have been taken by interna- tional communities to empower developing countries, especially low and middle income countries with free open access to medical journals and books. One such example is Health Inter Network Access to Internet Research Initiative (HINARI) by the World Health Organization. HINARI was developed to provide free or low-cost access to more than 1500 scientific and medical journals published by six major groups. ${ }^{6}$ In our study, while most of the participants were comfortable using computers and were using various resources, the above figures suggest that these medical students preferred popular search engines than scientific databases. This becomes a major obstacle to obtain reliable information because, Google ranks the websites based on a special algorithm with websites with advertising contracts are ranked higher than other. Furthermore, Wikipedia is an open source project that means anyone can alter the information in Wikipedia without proper citations. This again opens a window into a land of unreliable information. This issue can be addressed during a formal training session, where students will be taught to differentiate between good and poor sources.

Under the auspices of MEPI and Novel Education Clinical Trainees and Researcher's Program, students attended courses on EBM. But, our study reveals that only a minority of medical students felt they received adequate training in EBM (23\%) and Journal Club Presentation (7\%). (Table 3).

When questioned, the majority (trained and untrained) were keen to pass these courses again. This suggests an

\section{Table 3. Training in EBM and Journal club presentations}

\begin{tabular}{ll}
\hline Responders & No. in percent \\
$\begin{array}{l}\text { No formal training in EBM and Journal club } \\
\text { presentation }\end{array}$ & $67 \%$ \\
$\begin{array}{l}\text { Formal training received in EBM and Journal } \\
\text { club presentation }\end{array}$ & $23 \%$ \\
Did not answer & $10 \%$ \\
\hline
\end{tabular}


unmet need and an opportunity for growth. While medical students concur that bedside use of these hand-held devices and medical resources prove to be helpful in their training, careful analysis of the data shows that while addressing the technological issues, there is a need to address other issues such as providing adequate training in using these technologies until a comfort level is reached.

\section{Conclusion}

Efforts taken by international community to provide resources, funding and infrastructure to resource limited countries are laudable and have improved the quality of medical education and technology among participating institutions. Our study suggests that lack of training in EBM, journal club presentation, and analytical reading skills among this group have limited the impact of the upgraded technology and programs in enhancing the level of knowledge among medical students in UZCHS. In order to ensure maximum user acceptability, we suggest creation of a curriculum centered on equipping medical students in UZCHS with these necessary skills: devising a clinical question, reading medical literature with a critical eye in search of an answer, and utilizing available resources to build one's fund of knowledge. Supplementing the technological growth with EBM approaches could further enhance the healthcare initiatives and delivery.

\section{Limitations}

This is a small study. The study covers only one academic medical center. UZ is one of the institutions, that receives funding support from MEPI and therefore the results may not be generalizable to other African counterparts.

\section{Conflict of interest}

The authors have no conflict of interest to declare.

\section{Acknowledgements}

The study was funded by the Western Connecticut Health Network. The authors wish to acknowledge Leah Moody and Mary Shah for their review of the manuscript. A part of the study was published as an abstract and poster at the Consortium of Universities for Global Health Conference (CUGH-2015) in Boston, USA.

\section{References}

1. Davies BS, Rafique J, Vincent TR, Fairclough J, Packer $\mathrm{MH}$, Vincent $\mathrm{R}$, et al. Mobile Medical Education
(MoMEd) - how mobile information resources contribute to learning for undergraduate clinical students - a mixed methods study. BMC Med Educ [Internet]. 2012;12(1):1. Available from: http://www.scopus.com/inward/record. url?eid=2-s2.0-84855587344\&partnerID=tZOtx3y1

2. McNairy ML, Wurcel AG, Huang F, Daily JP. Health care workers in Africa access a broad range of topics using evidence-based online medical information. Glob Public Health [Internet]. 2012;7(8):823-39. Available from: http:/ / search.ebscohost.com/login.aspx?direct=true\&d $\mathrm{b}=\mathrm{a} 9 \mathrm{~h} \& A N=79291777 \&$ site $=$ ehost-live $\backslash$ nhttp: $/ /$ www. tandfonline.com/doi/pdf/10.1080/17441692.2012.6854 88

3. Ameh N, Kene TS, Ameh EA. Computer knowledge amongst clinical year medical students in a resource poor setting. Afr Health Sci [Internet]. 2008;8:40-3. Available from: http://ovidsp.ovid.com/ovidweb.cgi? $\mathrm{T}=\mathrm{JS} \& \mathrm{CSC}=\mathrm{Y} \& \mathrm{NEWS}=\mathrm{N} \& \mathrm{PAGE}=$ fulltext $\& \mathrm{D}=\mathrm{m}$ ed5\&AN=19357731.http:/ / sfx.scholarsportal.info/ uhn? sid=OVID:medline\&id=pmid:19357731\&id $=\mathrm{d}$ oi:\&issn $=1680-6905 \&$ isbn $=\&$ volume $=8 \&$ issue $=1 \&$ spag $e=40 \&$ pages $=40-3 \&$ date $=2008 \&$ title $=$ African + Health + Sci

4. Edejer TT-T. Disseminating health information in developing countries: the role of the internet. Br Med J. 2000;321:797-800. PubMed

5. Weeks AD. Closing the digital divide. Financial and technical obstacles must be eliminated. $\mathrm{Br}$ Med J [nternet]. 2003;326:1035. Available from: http://www.ncbi. nlm.nih.gov/pubmed/12749317

6. Katikireddi SV. HINARI: bridging the global information divide. Br Med J. 2004;328:1190-3.

7. Royall J, Schayk I V, Bennett M, Kamau N, Alilio M. Crossing the digital divide: the countribution of information technology to the professional performance of malariia researchers in Africa. Afr Health Sci. 2005;5(3):246 PubMed .

8. Kuruvilla S, Dzenowagis J, Pleasant A, Dwivedi R, Murthy N, Samuel R, et al. Digital bridges need concrete foundations: lessons from the Health InterNetwork India. Br Med J. 2004;328(7449):1193-6. PubMed

9. Williams CD, Pitchforth EL, O'Callaghan C. Computers, the Internet and medical education in Africa: Accessing technologies. Med Educ. 2010;44(5):485-8. PubMed 10. Africa Internet Usage and 2014 Population Stats [Internet]. 2014. Available from: http://www.internetworldstats.com/stats1.htm 
11. 2014 World Population Data Sheet. 2014.

12. Bagala JP, Macheka ND, Abebaw H, Wen LS. Implementation of the medical education partnership initiative: medical students' perspective. Acad Med [Internet]. 2014;89(8 Suppl):S32-4. Available from: http://www. ncbi.nlm.nih.gov/pubmed/25072574

13. Ndhlovu C, Nathoo K, Borok M, Chidzonga M, Aagaard E, Connors S, et al. Innovations to Enhance the Quality of Health Professions Education at the University of Zimbabwe College of Health Sciences - NECTAR Program. Acad Med. 2014;89(8):S88-92.

14. UZCHS. College of Health Sciences Faculty of Medicine [nternet]. Available from: http://www.uz.ac.zw/index.php/faculties/faculty-of-medicine
15. Talib ZM, Baingana RK, Sagay AS, Van Schalkwyk SC, Mehtsun S, Kiguli-Malwadde E. Investing in community-based education to improve the quality, quantity, and retention of physicians in three African countries. Educ Health (Abingdon). 2013;26(2):109-14.

16. Ajuwon GA. Computer and internet use by first year clinical and nursing students in a Nigerian teaching hospital. BMC Med Informatics Decis Mak [nternet]. 2003;3:10. Available from: http://login.ezproxy.library.ualberta. ca/login?url=http://ovidsp.ovid.com/ovidweb.cgi?T= $\mathrm{JS} \& \mathrm{CSC}=\mathrm{Y} \& \mathrm{NEWS}=\mathrm{N} \& \mathrm{PAGE}=$ fulltext $\& \mathrm{D}=\operatorname{med} 4 \&$ AN=14498997 http://resolver.library.ualberta.ca/resolv er?sid=OVID:medline\&id=pmid:14498997\&id=doi:\&is $\mathrm{sn}=1472-6947 \&$ isbn $=\&$ volume $=3 \& \mathrm{i}$ 